\title{
The Role of Leadership in the Development of the Creative School in Palestine
}

\author{
Suheir Sulieman Sabbah ${ }^{1}$ \\ ${ }^{1}$ Faculty of Educational Sciences, Department of Psychology, Al-Quds University, East Jerusalem-Abu \\ Dies, Palestine
}

\begin{abstract}
The world faces a great developmental revolution in all scientific fields which in its turn affects different aspects of life, such as: the medical, engineering and educational fields, etc. The educational school's aspect in particular will be the topic of this research. It tries to assist in developing the different aspects of the educational leader's character in order to be capable to work, conduct research, create and innovate through developing how to think and how to be a creative leader of a creative school. This study aims at recognizing the role of educational leadership in developing the creative school in Palestine. Two focus groups, each of which consists of 15 members, were met. According to their responses, a list of opinions and suggestions, that had been given to explain the educational role in developing a creative school, was applied to a small sample of 116 school's male and female leaders. Results showed high percentage in the role of educational leader of average 4.43 and a standard deviation of 0.29 . The highest percent was for the role of school's administration and class' environment followed by teacher's role and extra class activities respectively.
\end{abstract}

Keywords: Leadership, Creative school, Development, Palestine.

\section{Contents}

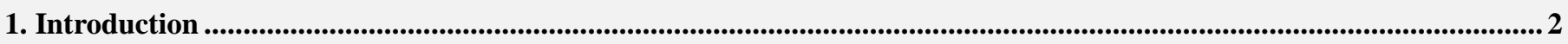

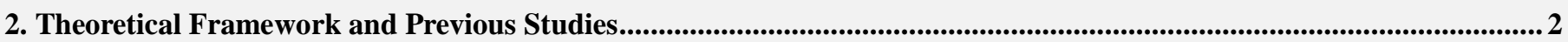

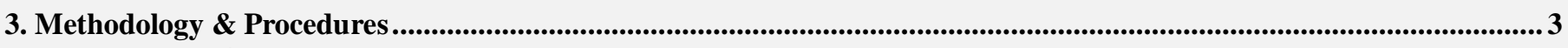

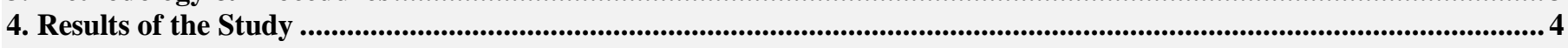

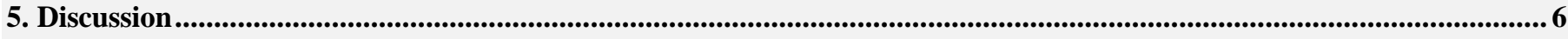

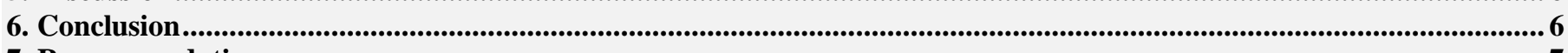

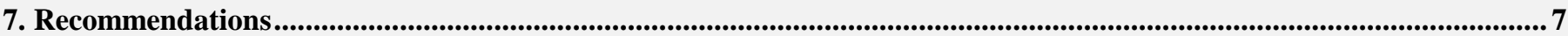

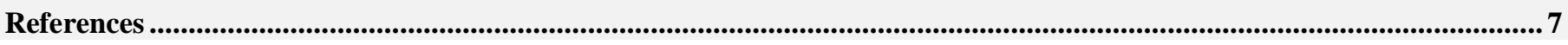

Citation | Suheir Sulieman Sabbah (2017). The Role of Leadership in the Development of the Creative School in Palestine. Journal of Education and eLearning Research, 4(1): 1-7.

DOI:

$\operatorname{ISSN}(\mathbf{E})$ :

$\operatorname{ISSN}(\mathbf{P})$ :

Licensed:

Funding:

Competing Interests:

Transparency:

History:

History:

Publisher: 10.20448/journal.509/2017.4.1/509.1.1.7 Crossref

$2410-9991$
$2518-0169$

This work is licensed under a Creative Commons Attribution 3.0 License $(c)$ EY

This study received no specific financial support.

The author declares that there are no conflicts of interests regarding the publication of this paper.

The author confirms that the manuscript is an honest, accurate, and transparent account of the study was reported; that no vital features of the study have been omitted; and that any discrepancies from the study as planned have been explained.

Received: 9 November 2016/ Revised: 13 December 2016/ Accepted: 9 January 2017/ Published: 6 February 2017

This study follows all ethical practices during writing.

Asian Online Journal Publishing Group 


\section{Introduction}

The world faces a great developmental revolution in all scientific fields which in its turn affects different aspects of life, such as: the medical, engineering and educational field...etc. The educational school's aspect in particular will be the topic of this research. It tries to assist in developing the different aspects of the educational leader's character in order to be capable to work, conduct research, create and innovate through developing how to think and how to be a creative leader of a creative school.

The educational leadership of this educational institution has an ambition, strong motivation and an integral readiness to adapt life requirements through revealing the hidden and creative power and encouraging the creative and innovative skills among the workers. So that creativity, innovation, and flexibility are the main engines which manages the educational learning process in the school (Sorour, 2002).

The activities which encourage creativity, observation and imagination are characterized by ambiguity and challenge; they are usually related to unusual situations that force students to search and investigate taking into consideration that some parts of these activities should be applicable to the extent that allow them to interact with their surrounding and improve their creative skills inside and outside school. This had positive effects on the students' behavior, thinking and creativity. Undoubtedly, there is a need for a creative, innovative, renewal and dynamic method in different aspects of administration (Al Khawaja, 2004).

Creativity leads to renewal and development. The creative leader, the main factor of school's success, should deal with modern civilization by trust and without frequent fear in its thoughts, without imitating others, or waiting their suggestions, thoughts and creativity. Therefore, Palestinian schools' leadership aims at creating a radical development in the educational process and its workers, which will affect teachers positively and help them to be effective members in their society.

This study aims to identify the participation of the educational leadership in developing creativity at schools as the principal, the educational leader in his institution, who affects in all other workers, encourages them to cooperate effectively, he is also responsible to achieve the desired educational targets, and clarify the desired applicable success.

\subsection{Questions of the Study}

The study's problem is identified in the following questions:

1- How does a leader see his role in developing the creative school?

2- What is the degree of the role of an educational leadership in developing the creative school?

\subsection{Objectives of the Study}

The study tries to achieve the following goals:

1- Identifying how an educational leader considers his role in developing the creative school.

2- Identifying the degree of the educational leader's role in developing the creative school.

\subsection{Significance of the Study}

The importance of this study comes from the importance of the school's educational leadership and its effective role, its cooperation in shaping the learning and educational process, its degree of involvement in developing the school's creativity environment and its encouragement to conduct many studies regarding the role of the educational leadership in developing the creative school.

This study is stimulant for workers in the leadership and administration of schools field to reveal how leaders see their roles in developing the creative school in order to support and take care of culture, creativity, renewal and innovation in Palestinian educational institutions along with preserving authenticity and modernism according to our values.

This study may inspire other researchers to study creativity culture and developing it, identify a number of activities and administrative artistic developing strategies. Those are used in discovering creative and innovator teachers as well as students, and in developing creativity and innovation in all life aspects. The conclusion and recommendations of this study will help in developing creativity in schools in general.

\subsection{Limitations of the Study}

The study is limited to educational leaders in public schools who were interviewed and answered a questionnaire in May, 2014.

\section{Theoretical Framework and Previous Studies}

The concept of creativity has been used as a synonym to other concepts like innovation, talent, intelligence, and superiority. It was frequently used in late $20^{\text {th }}$ century, considering it a one of the most important concepts that affect different institutions behaviors in present and future (Evan, 1999; Park, 2012). Therefore, there was no consensus about one definition of creativity, and was contextually used. AL Sherbini and Sadiq (2002) defined it as a process which points at a group of features, abilities and factors that show the attitude of a creative person in a high degree.

Abu and Ahmed (1992) define creativity as "The environment that paves the road for innovation and creativity; it is a set of factors and environmental circumstances which take part in its development. These circumstances are divided into two divisions; the circumstances which related to society and its culture in general and secondly, the school, teachers, principals and supervisors-related circumstances" (p. 15). However, Bernard (2003) pointed to the concept of creative leadership as the ability to produce thoughts.

One of the creative school features is that the school achieves its desired targets and takes care of the school's organizational frame which includes rules, tools, strategies, and it re-organizes work, and enhances the relations and cooperation between teachers and students. Moreover, it facilitates the administrative and educational services that 
exceed their expectations (AL Sultan, 2004). Creativity could be radical causing to produce radical changes in school or could be partial causing secondary changes. Creativity can be unplanned for, as well (Hijan, 1999).

Criteria for evaluating a creative school:

1- Creating a suitable educational environment that encourages thinking through taking care of all school's situations and adapting to the educational environment.

2- Focusing on practice for a long period through stimulating the students' thinking; attract their attention, focus and practice to all topics' aspects that should be changed.

3- Intensive redemption in order to stimulate memory and confirm all information and treat them thoroughly taking into consideration that all information are important even if they are secondary ones.

4- Strengthen thinking and accept students' positive attitudes and guiding them to what suits their abilities without neglecting their opinions.

5- Identifying the target in helping the student to shape out his opinion regarding his success, i.e., the student evaluates himself. In addition, helping the student to identify his points of strength and weakness in his work and thinking.

Bearing responsibility and strengthening the student's ability to learn independently, he will more confident in himself and his actual abilities (Dalloul and ALasi, 2008).

These criteria are related to a creative educational leadership through identifying the problem carefully with the ability to solve it due to the production of various ideas. It works on eliminating the resources used in solving problems, improving methods of working and solving the problems due to the originality of the idea (experts of specific experiences for managing center, 2004). Moreover, the creative behavior is considered the accurate and correct criterion for the change process as it is a stimulant for eliciting the best of leaders and helps in providing distinctive services to beneficiaries beyond their expectations. It also enhances the working environment through its openness, trust as well as it saves time and effort (Ventrla, 2003).

Furthermore, empirical research on the relationship between principal's leadership style and school innovation has highlighted principals as the agent or facilitator of innovation in schools (Park, 2012).

There were many studies that dressed the topic of creative leadership and its development. One of these studies was the study of AL Zahr (2013) which confirmed that the plenty of conditions and variables of creativity stimulants were met by the scarcity of creativity's production. The findings of the study of Pihie and Bagheri (2013) suggested that different aspects of principal's entrepreneurial leadership behavior improve the implemented organizational innovations and the changes they created in schools. The findings of Park (2012) indicated a significant impact of principals' leadership style on creating a supportive climate for school innovation. Yet, the influential effects of personal characteristics and leadership behavior of the principals on school innovativeness have not been explored (Hall and Hord, 2011).

Shammalh (2013); ALAgez and Sheldan (2010); Mredah (2007); Belwany (2008) agreed that the role of school's administration in developing creativity in schools was of a high degree and it cares mostly about production. It also defined the relation between teachers on a basis of tolerance and seriousness in work. However, in the final rank came the teachers' organization of scientific trips and competitions to stimulate creativity production and paying attention to the educational curricula.

These studies did not agree with AL Assaf (2004) which showed the absence of high creative levels of Female school's principles as the creativity reached a level of only $60 \%$. In addition, it showed that there were no differences in the creativity's levels of schools' principals according to (educational level, the experience in school's administration field, type of school, school's level, age, major, number of training programs) variables.

Nevertheless, the studies of Shammalh (2013); Belwany (2008) and showed that there were differences due to the gender variable. However, Al-Osaimi (2010) aimed at identifying the real educational and administrative roles of the school's administration that support creativity among students and these were as follows: the desire goals are: training for innovation, improving plans and programs, measuring student's innovative skills, using school's examinations to find out innovators and the allocation of specific classes to take care of them. Moreover, getting them involved in school's administration, evaluating its programs, creating the creative school's environment and practicing supervisory permissions to guide the educational process' elements towards creativity. Whereas the real roles are: organizing open days, showing creative works, permitting various students' activities, using programs for discovering and encouraging, in addition to the arrangement of competitions between students giving them the freedom to choose the activities.

\subsection{Comments on Previous Studies}

This study is in harmony with the previous studies in terms of the aims, the study's community, method and strategies. However, this study differs from the previous ones in the regional environment; this study was applied to the Palestinian community. This study is unique in that it focuses on improving school's creativity, while the majority of previous studies focused on the creativity of principals. Therefore, this study, according to the researcher's knowledge, is considered as one of the most superior studies in Palestine.

\section{Methodology \& Procedures}

\subsection{Method}

To achieve the objectives of the study, the analytical descriptive approach was used.

\subsection{Population of the Study}

The population of the study consisted of all educational leaderships at Palestinian schools. 


\subsection{Sample of the Study}

The researcher selected two groups of educational leaders in public schools. Each group consists of 15 male and female leaders. 109 members of educational leaders were chosen by a simple random sample.

\begin{tabular}{|c|c|c|c|}
\hline \multicolumn{2}{|l|}{ Variable } & \multirow{2}{*}{$\begin{array}{l}\text { Number } \\
51\end{array}$} & \multirow{2}{*}{$\begin{array}{l}\text { Percentage } \\
46.6\end{array}$} \\
\hline Gender & Male & & \\
\hline & Female & 58 & 53.4 \\
\hline \multirow[t]{3}{*}{ School's level } & Primary & 44 & 38.8 \\
\hline & Middle & 37 & 30.6 \\
\hline & Secondary & 38 & 30.6 \\
\hline \multirow[t]{3}{*}{ Educational degree } & Diploma & 14 & 13.2 \\
\hline & Bachelor's & 75 & 68.5 \\
\hline & Master's and above & 20 & 18.3 \\
\hline \multirow[t]{3}{*}{ Years of experience } & Less than 5 years & 22 & 20.5 \\
\hline & $5-10$ years & 29 & 26.5 \\
\hline & More than 10 years & 58 & 53.0 \\
\hline
\end{tabular}

\subsection{Instruments of the Study}

To identify the role of school's leadership in improving the creative school, the researcher organized two focus groups of educational leaders in public schools. In accordance with their responses and the review of literature and previous related studies, the two groups agreed on building a questionnaire of 61 items, divided into 4 categories. Lickert scale was used as follows: I strongly agree (5p), I agree (4p), I don't know (3.p), I disagree (2p), I strongly disagree (1p). This scale was applied to all items of study considering them positive ones.

Degree and means of the respondents' answers:

1. Average between $1-1.80$, very low,

2. Average between $1.80-2.60$, low,

3. Average between $2.60-3.40$, middle,

4. Average between $3.40-4.20$, high,

5. Average between $4.20-5$, very high

\subsection{Validity of the Instruments}

The questionnaire was designed initially, and it was checked and evaluated by a group of arbitrators to assert its suitability for the purpose and the correctness of forming the items, and to check the instrument validity by calculating Pearsons Correlation Coefficient of the total degree of the instrument, and it was clear that there was statistical significance in all the questionnaire's items which indicated internal validity among the items.

\subsection{Reliability of the Instruments}

To check the reliability of the study's instrument, the researcher calculated used Cronbakh Alpha and the total degree was (ranged between .84 and .93 , with a total of 0.96 ) which is considered appropriate for the study's purposes.

\section{Results of the Study}

Results related to the first question:

While interviewing the two focus groups (30 groups), the first is of male principals, and the second is of female principals, the following open-ended question was raised: How does an educational leader see his role in improving the creative school?

The answers of the two groups were as follows:

First of all, they confirmed that a successful leadership should have successful administrative skills. Moreover, they agreed that the success of any school's creativity depends largely on the school's educational leadership qualities. That is, the creative leader is one who experiences a set of the main qualities of creativity, whose effect should be seen in his attitude. Some of these are:

- Artistic skills which are characterized by bearing responsibility, profound understanding, determination, and belief.

- Self-skills like physical features, mental skills, intelligence, self-control and stability.

- Innovations, i.e. the courage to face difficult situations, choose alternatives and have fast reaction. This means, that the leader should not only be able to face difficult situations but to be capable to put plans to face the future.

It has a great role in creating a creative school featured of improving expert teachers, suitable class environment, suitable extra-curricular activities, and the complete design in terms of preparation as all cooperates in improving the creative school. So, school's leadership should be able to provide an educational environment which includes all activities that encourage discovery and imagination. It should be featured of ambiguity and challenge and be related to unusual actions. The administration's role affects the teacher's role inside the classroom. It is the school's administration that motivates the teacher to discover, research and investigate. Some of these activities should be applicable to the extent that allows the teacher to cooperate in the class and improve his skills inside and outside school. Consequently, this affects the students' behavior, thinking and creativity positively inside and outside the classroom.

Additionally, the two groups confirmed that leadership has an effective role in improving the creative school through encouraging the creative teacher who plays the main role in improving thinking skills. At the same time, the 
teacher provides the suitable environment for his students to get involved in extra- and class activities that involve solving real problems. To conclude, the successful leadership takes care of improving the teacher and the class environment to affect the students positively inside class. This, in turn, leads to creativity.

Moreover, school's leadership should allocate a specific budget to the extra-class activities that reflect creativity, especially, that the current school's environment lacks financial support that leads to improve these activities; consequently, affecting the degree of creativity improvement.

After asking the two groups about the range of difference between male and female principals in their view of a creative school, they answered that: "We all live in one society with its traditions and concepts that affect thinking either positively or negatively. So, any change in the ability of improving creativity inside the school may lead to specific skills among some leaders not among a specific gender. This will help in improving the environment from the point of view of individual differences.

They also confirmed that leadership needs to get their abilities, in dealing with each educational level according to its development, improved. And that all methods used in treatment differ according to the stage of study and the variety in students' nature, in addition to the necessity of parents' cooperation in improving the school.

The leadership's tasks to improve the creative school can be limited to:

On the administrative leadership basis: Firstly, Encouraging renewal and breaking the routine in school's environment. Secondly, evaluating the individual differences of teachers. Moreover, supporting the participation of teachers in training courses about creativity to improve their professional performance, In addition, giving the students the opportunity to express themselves and their needs, following them frequently and stimulating their individual creativeness, providing modern educational media devices, improving the library and the laboratories and the openness to professional and educational development.

On the base of developing teachers:

Interesting in creating encouraging educational environment, changing in methods and tools of evaluating students, creating a flexible and open environment, and giving students the opportunity to answer and think. In addition, stimulating students' learning motivation, accepting students' proposals about issues of interest to them, treating problems wisely, praising students' achievements in different occasions, providing a room in class for students for discussion, dividing tasks among students, the ability to pass information to students, variation in methods and strategies of teaching.

On the base of the cooperation of facilities and strategies in creating a creative school environment:

Providing students with modern strategies, school's building should be suitable in terms of area, suitability to educational activities, including yards for students, providing heating devices, wide classes for learning, and visual and aural learning resources. To have a creative school's environment with the cooperation of extra-class activities, the school should arrange for various scientific activities, activate the morning school assembly to display creative students' abilities, and initiate different programs. It should also arrange for educational programs, hold various competitions inside and outside school, plan activities about issues of interest to the society, organize discovery and scientific trips so as to link experiences acquired at school with those acquired outside. Moreover, variety in school's activities that include different students' levels, getting students involved in making some informational drawings inside school, improving students' artistic skills through drama, performing students' works inside and outside school, and getting parents and the local community involved in planning for school's activities.

Through discussions with the focus groups about the role of educational leadership in improving the creative school, it seems that they do not take the educational degree into consideration to the extent that it is affected by skills of the leadership itself, their special abilities, and the natural conditions under which they work. It is obvious to give higher degree holders evaluation which is higher than those leaders of first degrees for their roles in facing obstacles.

Results related to the second question: To what extent is the educational leader's role in improving the creative school?"

Table-2. Shows the role of school's leadership in improving the creative school

\begin{tabular}{l|l|l|l|l|l}
\hline Number of field & Field & Number & Average & Standard deviation & Degree \\
\hline First & The role of educational leadership in school & 109 & 4.49 & 0.34 & Very high \\
\hline Second & The role of extra-class activities & 109 & 4.28 & 0.45 & Very high \\
\hline Third & The role of teacher & 109 & 4.45 & 0.38 & Very high \\
\hline Fourth & The role of class environment & 109 & 4.49 & 0.41 & Very high \\
\hline Total degree & & 109 & 4.43 & 0.29 & Very high \\
\hline
\end{tabular}

The above table shows that the most important leadership roles in improving creativity among schools from the respondents' point of view is (The role of educational leadership in school and the role of class environment) with an average of 4.49 , very high degree. In the second rank, comes the role of teacher with a high degree with an average 4.45. Finally, the role of extra-class activities came in the last rank with an average of 4.28 , very high as well. However, the total degree was very high, too, with an average of 4.43 and a standard deviation of 0.29.

Secondly: Results related to gender, educational level, qualifications, and experience years: Means and standard deviations were calculated to the sample with leadership role in improving the creative school attributed to the degree of variable

Found that there are no statistical significant differences at $(0.05 \geq \alpha)$ according to gender on the total degree, where the mean of the total degree for males was (4.40), whereas the mean (4.45) for females, and also found that the calculated $T$ value $(-1.110)$. Found that there are statistical significant differences at $(0.05 \geq \alpha)$ level in the degrees of the school leadership role in improving the creative school according to the school level variant. 
Table-3. Means and standard deviations of various subscales

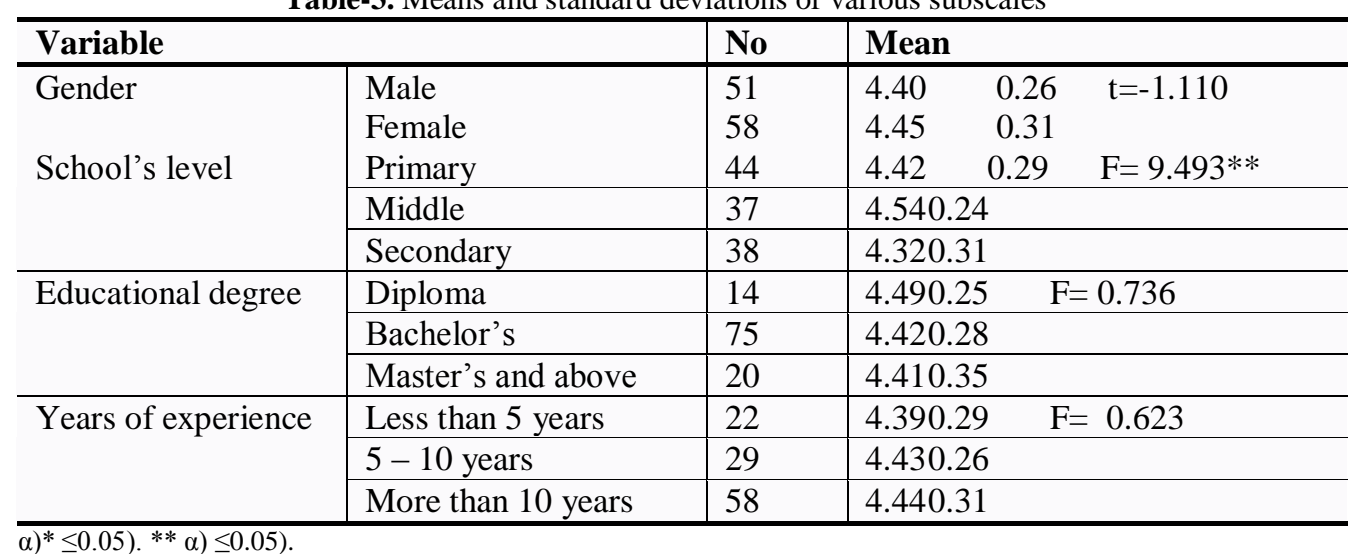

To know the distinction source and test the significance direction, the researcher used Sheffe test, the results indicated that the differences was in due to the higher means, where post Hoc comparisons indicate the differences between the middle school and secondary in favor to middle school. Also, the researcher found that there are no significant differences at $(0.05 \geq \alpha)$ for total degree of qualification and work experience variants.

\section{Discussion}

Results showed the importance of educational leadership in the first degree among all other roles in improving the creative school. Thus, the success of any school depends, on the first place, on the school's leadership skills and abilities. The creative principal is the one who has a set of basic skills for creativity that affect his/her attitude. Results also showed the importance of leadership in supporting the teacher's role in improving creativity as one of the most important roles of the school's environment and the latter came in the second rank. Thus, the positive teacher is the one who plays a main role in improving creativity and thinking, and he/she is the one who offers the suitable environment for his/her students to get involved in extra-class and in-class activities that involve solving real problems, and the field of extra-class activities came in the third rank. According to the researcher, this result was attributed to the schools' allocation of a specific budget to extra-class activities that are related to creativity. The results also showed that the total degree of the educational leadership was very high as well. These results agree with the studies of Mredah (2007); Shammalh (2013); ALAgez and Sheldan (2010); Belwany (2008) and they disagreed with AL Assaf (2004) which showed the absence and the inferiority of high creative levels of schools' female principals.

Moreover, the results showed that all leaders are subjected to one educational system because the rules of schools are unified and the responsibilities of schools' principals do not differ according to gender. In addition, the conditions under which the Palestinian nation lives are one of these factors. Moreover, there is no single difference in curricula which all principals take during their educational preparation. However, results of this study differed with that of Belwany (2008).

Leadership has to take care of the educational level in general, and the primary level that signifies the stage of early teenage in particular; this includes facilitating all environment possibilities and motivating all teenager qualities to guarantee learning, as well as, taking a look at all knowledge resources outside school, evaluating them, choosing from them, and using them positively in the mental growth of a teenager. In addition, it includes facilitating all experiences which allow a growth in thinking and encourage creative talents taking into consideration that learning in this stage should aim at achieving mental, physical, reactive, social and spiritual growth. On the other hand, the focus is on the primary and middle levels is on providing learning possibilities that guarantee a growth in child's abilities to his utmost to be a good human in his society. Besides, working on improving talents and interests by answering the entire child's questions, and improving creativity among children through learning music, performing and art which indicates the need of educational leaders at primary schools to improve their abilities in dealing with each educational level according to its development. Therefore, the methods used in dealing with the higher primary level may vary according to the nature of students. It may also be attributed to the fact that higher primary schools' principals who may need specific preparations that allow them to deal with students at this stage, which requires specific preparations that the teachers of middle and lower levels may not need them because they are dealing with students of less understanding abilities.

The researcher noticed through discussion that leaders with long experience are more accurate when it comes to the vision of improving the dominant school as they always aspire to the integral quality. In addition to taking part in various intensive courses that are held by the Palestinian Ministry of Education, they could through their experience and long service have their own strategies and ways in dealing with the school's environment including its students, teachers, local community, and educational administration. Moreover, they could construct trust with all parties of interest in improving creativity.

The researcher also noticed that the two focus groups didn't focus on the role of parents and the parents' council and local institutions in improving the creative school. The researcher attributed this for their secondary view of the parents' role in supporting the school which hinders the constant communication between them. Moreover, rules and instructions did not give a great importance to parents and community institutions.

\section{Conclusion}

This study aims at recognizing the role of educational leadership in developing the creative school in Palestine. Two focus groups: each of which consists of 15 members, were met. According to their responses, a list of opinions and suggestions was given to explain the educational role in developing a creative school. Results showed high 
percentage in the role of educational leader of average. The highest percent was for the role of school's administration and class environment followed by teacher's role and extra class activities, respectively.

\section{Recommendations}

Based on the previous results, the researcher recommends the following:

1- The necessity of taking care of extra-class activities due to their important role in improving the creative school.

2- Activating the parents' and community institutions' role in school's activities

3- Increasing the budget allocated to school's activities.

4- Extension of training courses for administrative leadership of schools that help them acquire administrative creativity skills and use them in their work.

5- Choosing mature leaders who believe in the importance of creativity in school's environment and work on improving it with teachers and learners.

6- Conducting further studies about the obstacles that face school's leadership in improving the creative school along with strategies of solving them.

7- Encourages other researchers to study culture and improve it, identify a set of activities and improve administrative and artistic strategies that are used in discovering innovators and creative teachers and students, and these are used in improving creativity and innovation in all aspects of life.

\section{References}

Abu, H.Y. and A. Ahmed, 1992. The impact of educational level and sex in the ability to innovative thinking. Journal of Social Affairs, the United Arab Emirates, 9(36): 44-60.

Al-Osaimi, K.M., 2010. The role of school management in supporting innovation among students. Journal of Um al-Qura, 2(2): 174-238.

AL Assaf, W., 2004. The fact of creativity and its obstacles to the principals of schools in Riyadh. Unpublished MA Thesis, King Saud University.

Al Khawaja, A., 2004. Development of the school administration. Dar AL Thaqafah, Amman, Jordan.

AL Sherbini, Z. and Y. Sadiq, 2002. Children at the top: The talent, mental superiority, creativity. Egypt: Dar Alfekr Arabi.

AL Sultan, F., 2004. Managerial challenges in the twenty-first century. Riyadh: Immortal Offset Printing Press.

AL Zahr, K., 2013. Creativity student in the university community Algerian between the incentive and the characteristics of the middle destructive variables. A Book Conference: Part I, (Research Presented at the First International Conference of the Deanship of Student Affairs: University Students / Reality and Hopes) The Islamic University, Gaza, Palestine, from 13 - 14 / February, pp: 100117.

ALAgez, F. and K. Sheldan, 2010. The role of school leadership in the development of creativity among teachers of secondary school governorates of the Gaza Strip from the point of view of teachers. Journal of the Islamic University (Humanities Series), $18(1)$ : 1- 37.

Belwany, A.S., 2008. The role of the school administration in the development of creativity in the development of schools in the public schools in of Northern Palestine and obstacles from the viewpoint of its directors. (Unpublished Thesis) MA, College of Education, AnNajah National University, Nablus.

Bernard, S., 2003. Creative manager, retrieved from creative-manager-lesson.Htm. Retrieved from http://www.prm.nau.edu/prm426/.

Dalloul, A. and W. ALasi, 2008. Social materials and methods of teaching. 2nd Edn., Gaza, Palestine: Al-Aqsa University.

Evan, S.J., 1999. Creative thinking in the decision management sciences. Cincinnati. Ohio: South Western Publishing Co.

Hall, G.E. and S.M. Hord, 2011. Implementing change: Patterns, principles and potholes. 3rd Edn., Boston, MA: Pearson.

Hijan, A.A., 1999. Obstacles to innovation organizations in Saudi Arabia. Public Administration From, 39(1): 1-77.

Mredah, N.S., 2007. The relationship between leadership behavior and administrative innovation of the subordinates. A field study on the employees of King Abdul Aziz University, Unpublished MA Thesis, University of King Abdul Aziz.

Park, J.H., 2012. The effects of principal's leadership style on support for innovation: Evidence from Korean vocational high school change. Asia Pacific Education Review, 13(1): 89-102. View at Google Scholar | View at Publisher

Pihie, Z.A. and A. Bagheri, 2013. The impact of principals' entrepreneurial leadership behavior on school organizational innovativeness. Life Science Journal, 10(2): 1033-1041. View at Google Scholar

Shammalh, P.A., 2013. The role of the school management in the evelopment of creativity among teachers in public education provinces of Gaza from their point of view. The Fifth Annual Conference (The Development of a Culture of Innovation the Ministry of Culture of the Palestinian National, the site of the Ministry of Culture.

Sorour, N., 2002. Introduction to creativity. 1st Edn., Amman: Dar Weal for Printing and Publishing.

Ventrla, A., 2003. Creativity future of the management. Malaysia: University of Oceania. 